\title{
Desain Video Pembelajaran Matematika dengan Aplikasi Microsoft Office Powerpoint
}

\author{
Kunsa'aidah* \\ SMPN 4 Monta, Bima, Indonesia \\ *Coresponding Author: kunsaaidah@yahoo.com \\ Dikirim: 29-06-2021 ; Direvisi: 04-07-2021 ; Diterima: 05-07-2021
}

\begin{abstract}
Abstrak: Pelaksanaan pembelajaran matematika menjadi sesuatu yang dipandang sulit bagi kebanyakan siswa, hal ini memerlukan perhatian yang serius bagi guru matematika dalam mengajarkan matematika. Hasil observasi pada mata pelajaran matematika di SMPN 4 Monta motivasi belajar siswa cenderung rendah, yang disebabkan oleh Siswa kurang memperhatikan pada saat guru menjelaskan materi pelajaran, guru hanya memanfaatkan media papan tulis untuk menyampaikan dan menerangkan materi, dan Kemampuan dan pengetahuan guru tidak dapat ditrasfer dengan maksimal karena ketiadaan media pembelajaran yang menarik. Oleh karena itu, perencanaan yang baik oleh guru matematika sangat menentukan minat dan motivasi siswa terhadap pelajaran matematika. Perkembangan ilmu pengetahuan dan teknologi menjadi faktor yang memperngaruhi pembelajaran matematika. Mengajarkan matematika pada siswa SMP memerlukan bantuan dari lingkungan untuk membantu mereka memenuhi tugas perkembangannya, dan pemanfaatan teknologi menjadi faktor penting yang membuat siswa dapat belajar dengan efektif. Salah satunya melalui penerapan media pembelajaran berbasis computer melalui desain video pembelajaran matematika dengan aplikasi microsoft office powerpoint. Hasil desain ini memberikan dampak yang baik terhadap siswa SMPN 4 Monta dalam mengikuti dan memahami pembelajaran matematika. Siswa lebih semangat mengikuti pelajaran karena visualisasi vidio yang ditampilkan, kemudian siswa mudah memahami pelajaran matematika karena materi sudah didesain dengan terstruktur.
\end{abstract}

Kata Kunci: vidio pembelajaran; pembelajaran matematika; microsoft office powerpoint

Abstract: The implementation of mathematics learning becomes something that is considered difficult for most students, this requires serious attention for mathematics teachers in teaching mathematics. The results of observations on mathematics subjects at SMPN 4 Monta tend to be low, which is caused by students not paying attention when the teacher explains the subject matter, the teacher only uses the blackboard media to convey and explain the material, and the ability and knowledge of the teacher cannot be transferred by maximum due to the absence of interesting learning media. Therefore, good planning by mathematics teachers will determine students' interest and motivation towards mathematics. The development of science and technology is a factor that affects the learning of mathematics. Teaching mathematics to junior high school students requires assistance from the environment to help them fulfill their developmental tasks, and the use of technology is an important factor that enables students to learn effectively. One of them is through the application of computer-based learning media through the design of mathematics learning videos with the Microsoft Office PowerPoint application. The results of this design have a good impact on the students of SMPN 4 Monta in following and understanding mathematics learning. Students are more enthusiastic about taking lessons because of the video visualization that is displayed, then students can easily understand mathematics because the material has been designed in a structured manner.

Keywords : learning video; mathematics learning; microsoft office powerpoint 


\section{PENDAHULUAN}

Perkembangan ilmu pengetahuan dan teknologi yang begitu pesat dan sejalan dengan perkembangan era globalisasi yang sekarang sedang gencar dibicarakan, maka perlu upaya untuk meningkatkan sumber daya manusia (SDM) untuk menghadapi dampaknya. Fungsi pendidikan nasional sebagaimana yang dicantum dalam Undang-Undang Sistem Pendidikan Nasional No. 20 Tahun 2003 pasal 3 (Depdiknas, 2003) adalah untuk mengembangkan kemampuan dan membentuk watak serta peradaban bangsa yang bermartabat dalam rangka mencerdaskan kehidupan bangsa. Salah satu upaya untuk mewujudkan tujuan dan fungsi pendidikan nasional tersebut adalah dengan meningkatkan mutu pendidikan.

Sekolah Menengah pertama (SMP) adalah merupakan jembatan antara sekolah dasar dan sekolah menengah umum. Pelajar sekolah menengah Pertama (SMP) umumnya berusia 13 - 15 tahun, Berdasarkan tugas perkembangan yang dijabarkan oleh Havighurst (1976), anak-anak usia tersebut memerlukan bantuan dari lingkungan untuk membantu mereka memenuhi tugas perkembangannya. Salah satu pihak yang membantu dan turut berperan dalam perkembangan anak adalah sekolah. Anak usia sekolah menghabiskan sekitar 1/3 hari mereka di sekolah. Guru dalam hal ini yang akan memberikan materi-materi mempunyai peran penting untuk memfasilitasi hal-hal yang diperlukan anak di sekolah dan guru juga dituntut untuk bisa menyajikan materi pembelajaran yang menarik dan tidak membosankan bagi peserta didik. Perkembangan intelektual dapat dicapai melalui proses belajar mengajar secara formal di sekolah, berdasarkan kurikulum pendidikan yang telah dirumuskan.

Tujuan pendidikan yaitu membentuk manusia yang berwatak, mendidik anakanak agar dapat berpikir secara rasional, bekerja beraturan dan sungguh-sungguh menanamkan rasa persatuan, membentuk manusia yang bebas dan merdeka serta percaya diri dan bertanggung jawab, membentuk pribadi yang aktif mengabdi dan membangun masyarakat, mengembangkan manusia seutuhnya, yakni yang bertaqwa kepada Tuhan Yang Maha Esa dan berbudi pekerti luhur serta memiliki pengetahuan yang mumpuni. Persamaan antara pendidikan, pembelajaran dan pengajaran. Semuanya akan dapat mencapai tujuan jika pembelajaran bermakna dengan pengajaran yang tepat.

Berdasarkan hasil observasi penulis selama mengajar mata pelajaran matematika di SMPN 4 Monta motivasi belajar siswa cenderung rendah, hal ini dapat disebabkan oleh: siswa kurang memperhatikan pada saat guru menjelaskan materi pelajaran. Hal ini terlihat pada proses pembelajaran, Siswa tidak mencatat dan terlihat mengobrol dengan temannya; Kemudian pada saat pembelajaran, guru hanya memanfaatkan media papan tulis untuk menyampaikan dan menerangkan materi; serta kemampuan dan pengetahuan guru tidak dapat ditrasfer dengan maksimal karena ketiadaan media pembelajaran yang menarik.

Untuk mengatasi hal tersebut, perlu adanya perubahan metode pada proses pembelajaran. Salah satunya melalui penerapan sebuah media pembelajaran berbasis komputer untuk menunjang proses pembelajaran. Seperti kita ketahui media pembelajaran saat ini bermacam-macam jenisnya. Terlebih lagi ketika teknologi dan multimedia semakin berkembang, media pembelajaran yang muncul semakin banyak sehingga membantu berlangsungmya proses pembelajaran. Guru/pengajar dapat menyampaikan materi melalui media pembelajaran yang telah ditentukan agar tujuan 
pembelajaran dapat dicapai dengan baik. Media pembelajaran berbasis multimedia merupakan media pembelajaran yang memanfaatkan penggabungan antara gambar, suara atau audio, dan video. Film danVideo merupakan contoh media pembelajaran berbasis multimedia yang dapat dimanfaatkan untuk penyampaian materi. Dalam tulisan ini, akan dibahas mendalam mengenai apa itu video pembelajaran dan bagaimana mendesain sebuah video pembelajaran yang bisa digunakan untuk menyampaikan materi kepada peserta didik agar peserta didik bisa lebih semangat dalam belajar.

Mengingat pentingnya media pembelajaran guna mengingat fungsi dari media pembelajaran sebagaimana yang telah dipaparkan di atas, maka media pembelajaran yang akan dibuat harus memuat materi pelajaran, simulasi atau gambar. Pengunaan simulasi atau gambar pada media pembelajaran dapat dilakukan melalui penerapan media pembelajaran berbasis multimedia (media pembelajaran berbantuan komputer), salah satunya adalah dengan menggunakan bantuan program aplikasi Microsoft Office PowerPoint.

Microsoft Office PowerPoint merupakan sebuah software yang dikhususkan untuk melakukan suatu presentasi. Presentasi adalah istilah untuk menyampaikan suatu penjelasan baik secara visual ataupun non-visual kepada para pendengar. Karena pada dasarnya proses pembelajaran merupakan penyampaian informasi dan penjelasan pelajaran dari seorang guru terhadap para siswa.

Seiring perkembangan zaman, terutama dalam hal teknologi, semakin banyak keuntungan yang didapatkan apabila kita mampu mengimbanginya. Di tengah pandemi Covid-19 yang tengah melanda dunia, proses belajar mengajar pun mengalami perubahan yang luar biasa. Apabila sebelumnya guru/pengajar terbiasa memberikan materi secara klasikal melalui buku atau modul atau yang disebut dengan istilah pembelajaran luring yang berlangsung pada waktu dan ruangan yang bersamaan antara guru dan siswa (Syarifuddin dkk, 2021), sekarang bahan ajar umumnya berbasis e-learning (Khotimah dkk, 2021), yang diberikan melalui media online, berupa e-book, kelas digital, atau video pembelajaran.

Dengan pertimbangan di atas, maka perlu mendesain atau mengembangkan media pembelajaran matematika berbasis vidio menggunakan aplikasi Microsoft office powerPoint untuk menyajikan materi pelajaran yang menarik pada peserta didik sehingga bisa meninggkatkan motivasi belajar dan peserta didik bisa merasakan pembelajaran yang bermakna, karena selain untuk media pembelajaran di sekolah video pembelajaran ini juga bias dikirim ke smartphone peserta didik sehingga dapat dipelajari kapanpun dan dimanapun.

\section{KAJIAN TEORI}

\section{Media Pembelajaran}

Kamus besar Bahasa Indonesia (2001) kata media berate 1). Alat (sarana komunikasi seperti Koran, majalah, radio, televise, film, poster). 2). Yang terletak di antara dua pihak (orang, golongan dsb). Sedangkan Aryad (1997) mengungkapkan bahwa kata media berasal dari bahasa latin yaitu medius yang secara harfiah berarti tengah, perantara atau pengantar.

Kamus besar Bahasa Indonesia (2001) pembelajaran berasal dari kata ajar, ajar artinya petunjuk yang diberikan kepada orang lain supaya diketahui, Pembelajaran adalah proses, cara, perbuatan menjadikan orang atau mahluk hidup belajar. 
Sehingga pengertian media pembelajaran seperti yang dijelaskan Hamalik (1986) media pembelajaran yaitu metode dan tehnik yang digunakan dalam rangka lebih mengefektifkan komunikasi dan interkasi antara guru dan siswa dalam proses pendidikan dan pengajaran di sekolah. Dijelaskan lebih spesifik dalam Arsyad (1997) secara khusus pengertian media dalam proses belajar mengajar lebih cenderung diartikan sebagai alat tulis grafis, fotografis, atau elektronik uuntuk menagkap, memproses dan menyusun kembaliinformasi visual atau verbal.

Dari beberapa teori yang telah dipaparkan di atas dapat disimpulkan bahwa media pembelajaran adalah alat bantu atau benda yang digunakan untuk menunjang proses pembelajaaran itu sendiri, dengan maksud untuk menyampaikan materi ajar dari sumber (guru dansumber lain) kepada penerima pesan (siswa).

\section{Fungsi Media Pembelajaran}

Fungsi dari media pembelajran adalah sebagai alat bantu dalam proses belajar mengajar untuk memberikan pengalaman visual kepada peserta didik sehingga dapat meningkatkan motivasi belajar dan mempertinggi daya serap peserta didik, pada akhir tahun 1950 teori komunikasi mempengaruhi penggunaan alat bantu audio visual sehingga fungsi dari media pembelajaran sebagai peraga bergeser menjadi penyalur pesan atau informasi belajar (Miarso, 1984).

Hamalik (1986) mengemukakan bahwa pemakaian media pengajaran dalam proses belajar mengajar dapat membangkitkan keinginan dan minat yang baru, membangkitkan motivasi dan rangsangan kegiatan belajar, dan bahkan membawa pengaruh-pengaruh psikologis terhadap siswa. Secara umum, manfaat media dalam proses pembelajaran adalah memperlancar interaksi antara guru dengan siswa sehingga pembelajaran akan lebih efektif dan efisien. Tetapi secara lebih khusus ada beberapa manfaat media yang lebih rinci menurut Kemp \& Dayton (1985) yaitu penyampaian materi pelajaran dapat diseragamkan, proses pembelajaran menjadi lebih jelas dan menarik, proses pembelajaran menjadi lebih interaktif, efisiensi dalam waktu dan tenaga, meningkatkan kualitas hasil belajar siswa, media memungkinkan proses belajar dapat dilakukan dimana saja dan kapan saja, media dapat menumbuhkan sikap positif siswa terhadap materi dan proses belajar, dan merubah peran guru ke arah yang lebih positif dan produktif.

Selain beberapa manfaat media seperti yang dikemukakan oleh Kemp dan Dayton tersebut, tentu saja kita masih dapat menemukan banyak manfaat-manfaat praktis yang lain. Manfaat praktis media pembelajaran di dalam proses belajar mengajar diantaranya, media pembelajaran dapat memperjelas penyajian pesan dan informasi sehingga dapat memperlancar dan meningkatkan proses dan hasil belajar; media pembelajaran dapat meningkatkan dan mengarahkan perhatian anak sehingga dapat menimbulkan motivasi belajar, interaksi yang lebih langsung antara siswa dan lingkungannya, dan kemungkinan siswa untuk belajar sendiri-sendiri sesuai dengan kemampuan dan minatnya; media pembelajaran dapat mengatasi keterbatasan indera, ruang dan waktu; dan media pembelajaran dapat memberikan kesamaan pengalaman kepada siswa tentang peristiwa-peristiwa di lingkungan mereka, serta memungkinkan terjadinya interaksi langsung dengan guru, masyarakat, dan lingkungannya misalnya melalui karya wisata. Kunjungan-kunjungan ke museum atau kebun binatang (Arsyad, 2007). 


\section{Video Pembelajaran}

Beberapa pakar Pendidikan memberikan definisi video pembelajaran diantaranya Arief (2009) menyatakan video adalah media audio visual yang menampilkan gambar dan suara. Pesan yang disajikan berupa fakta (kejadian, peristiwa penting, dan berita) maupun fiktif (seperti misalnya cerita), bisa bersifat informatif, edukatif,maupun instruksional.

Menurut Arsyad (2011), media video yang digunakan dalam proses belajar mengajar memiliki banyak manfaat dan keuntungan, diantaranya video merupakan pengganti alam sekitar dan dapat menunjukkan objek yang secara normal tidak dapat dilihat peserta didik, misalnya materi proses pencernaan makanan dan pernafasan. Video dapat menggambarkan suatu proses secara tepat dan dapat dilihat secara berulang-ulang, mampu mendorong dan meningkatkan motivasi peserta didik untuk tetap melihatnya.

\section{Program Aplikasi Microsoft Office Powerpoint}

Microsoft office Powerpoint merupakan suatu perangkat lunak yang diciptakan khusus untuk menangani perancangan presentasi grafis secara mudah dan cepat. Dengan menggunakan Microsoft office Powerpoint kita dapat merancang presentasi visual yang menakjubkan menggunakan teks, grafis, foto, animasi, video, dsb (Anggawirya, 2011).

Microsoft Office PowerPoint banyak digunakan oleh kalangan perkantoran dan pebisnis, para pendidik, siswa dan trainer karena memiliki beberapa keuntungan seperti pengoperasionalan yang mudah sederhananya tampilan ikon-ikon dan tidak harus mempelajari bahas program komputer. Meskipun program aplikasi ini sebenarnya merupakan program untuk membuat presentasi namun fasilitas yang ada dapat dipergunakan untuk membuat media pembelajaran. Media pembelajaran yang dihasilkan akan cukup menarik karena memilik beberapa fasilitas seperti:

a. Memasukkan teks, gambar, suara dan video

Fasilitas yang penting dari program aplikasi ini adalah fasilitas untuk menampilkan teks. Dengan fasilitas ini pembuat program bisa menampilkan berbagai teks untuk berbagai keperluan misalnya untuk pembelajaran menulis, membaca atau pembelajaran yang lain. Selain itu juga dilengkapi dengan fasilitas tampilan gambar, suara dan video untuk memperjelas materi yang disampaikan.

b. Membuat tampilan menarik

Ada beberapa fasilitas yang disediakan untuk membuat tampilan menarik. Fasilitas yang pertama adalah background. Background akan memperindah tampilan program. Fasilitas lain yang akan membuat tampilan lebih menarik adalah fasilitas animasi. Dengan fasilitas ini gambar-gambar dan teks akan muncul ke layar dengan cara tampil yang bervariasi.

c. Membuat hyperlink

Hyperlink atau hubungan dalam satu program akan memungkinkan memberikan umpan balik secara langsung. Hubungan dengan program lain akan memperkaya fasilitas yang mendukung seperti halnya dalam proses pembelajaran dan hubungan dengan internet akan membuka berbagai kemungkinan pembelajaran yang lebih luas, pribadi dan otentik Fasilitas ini sangat penting dan sangat mendukung, dengan hyperlink program bisa terhubung ke program lain atau ke jaringan internet. 


\section{Fitur Microsoft Powerpoint}

Microsoft Office power point dapat digunakan dalam berbagai bidang. Fungsinya pun dapat bermacam-macam, bergantung pengetahuan penggunanya, sehingga power point tak hanya berperan sebagai media presentasi saja. Berikut bagian-bagian dalam microsoft office power point yang tersedia di dalam menu bar.

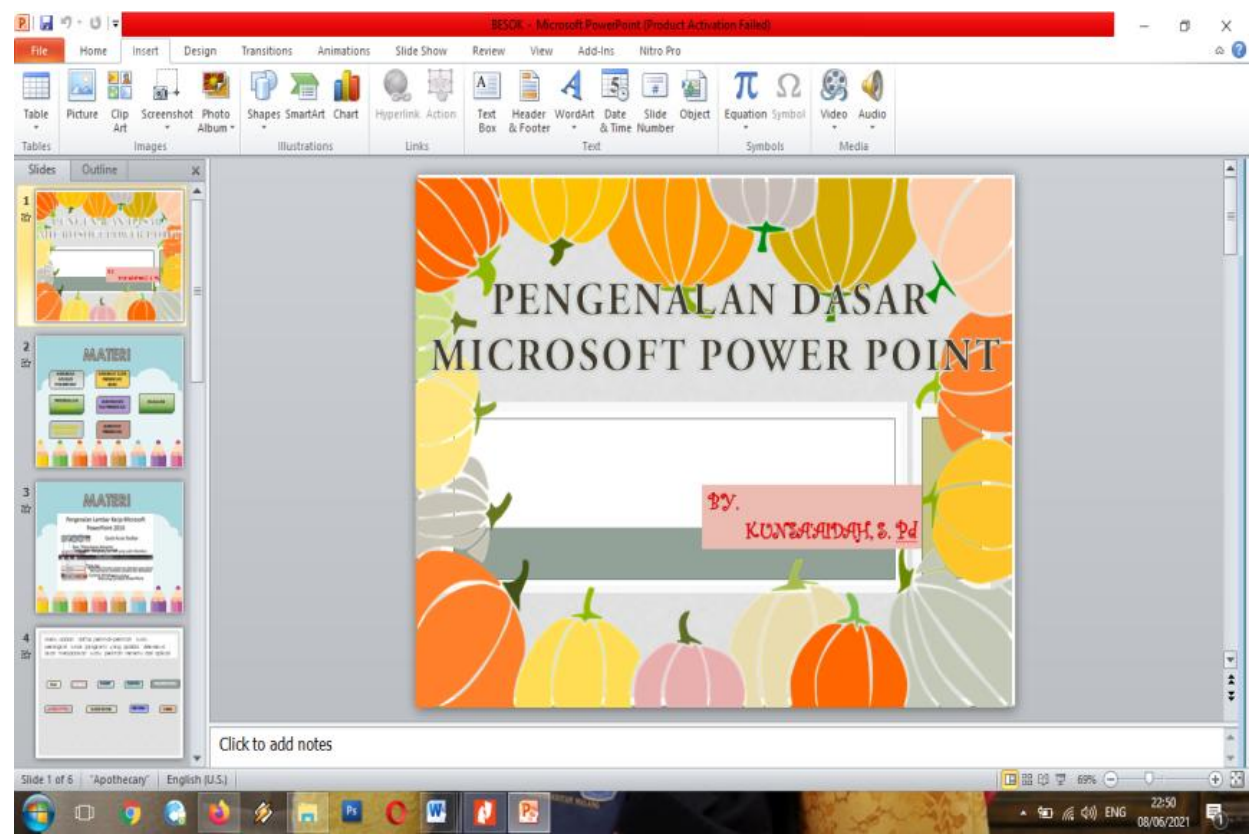

Gambar 1. Menu bar Power Poin

1. Menu File

Menu file ini memiliki fitur sebagai berikut:

$\checkmark$ Open, berfungsi untuk membuka file dokumen yang jenisnya power point atau dokumen. Power point biasanya disebut sebagai .ppt berarti file yang dibuka dikhususkan bagi file berbentuk power point.

$\checkmark$ New, fungsi dari fitur ini adalah membuka lembar baru atau membuat dokumen baru dalam file dokumen yang serupa.

$\checkmark$ Recent, fitur ini berfungsi untuk membuka file yang sudah Anda buka sebelumnya fitur ini seperti history dalam mozilla firefox. Anda tidak perlu susah payah mencari file yang sudah Anda buka. Cukup cari file dokumen di recent maka Anda akan menemukan dokumen yang Anda cari.

$\checkmark$ Save \& save as, jika Anda hendak menyimpan file baru yang belum pernah disimpan fungsi dari keduanya sama, tetapi jika Anda menggunakan fitur ini ketika Anda sudah menyimpan data Anda di komputer maka fungsinya berbeda. Save akan menyimpan perubahan data pada file lama, sedangkan save as menyimpan file dengan menciptakan file baru.

$\checkmark$ Print, berfungsi utnuk mencetak file dokumen ke dalam bentuk fisik

2. Menu HOME

$\checkmark$ Clipboard, fitur ini membantu dalam menyalin dan menempelkan objek yang sudah Anda salin di luar power point.

$\checkmark$ Slides, fitur ini berhubungan dengan halaman slide atau bagian-bagian halaman yang disambungkan oleh slide yang lian. 
Font, fitur font berfungsi untuk mengatur font, mulai dari ukurannya sampai jenis font yang akan Anda pakai.

$\checkmark$ Paragraph, fitur ini digunakan ketika Anda ingin membenahi hal-hal yang bersangkutan dengan paragraf.

$\checkmark$ Drawing, berfungsi untuk membubuhkan bentuk, desain dan garis pada halaman slide yang pilihan.

\section{Menu Insert}

Insert merupakan menu yang berhubungan dengan penyisipan suatu benda atau suatu media lain agar power point yang dibuat dapat dinikmati dan menarik audien. Fitur-fiturnya yakni seperti:

$\checkmark$ Tables yang berfungsi membubuhkan tabel pada slide

$\checkmark \quad$ Images yang berfungsi membubuhkan gambar.

$\checkmark$ Illustration berfungsi untuk menggambarkan ilustrasi,

$\checkmark$ Links berfungsi untuk menghubungkan, Text berfungsi untuk membubuhkan teks yang variatif,

$\checkmark$ Symbol mirip sebuah susunan rumus dan

$\checkmark$ Media berguna untuk membubuhkan media berupa audio dan video.

4. Menu Desain

Menu design memiliki fitur sebagai berikut.

$\checkmark$ Page setup, berfungsi untuk mengubah ukuran halaman slide dan orientasi slide, portrait atau landscape.

$\checkmark$ Themes, berfungsi sebagai desain dari background yang sudah ada ketika power point dipasang di komputer.

$\checkmark$ Background, fitur ini berfungsi untuk mengubah background sesuai keinginan Anda, bahkan Anda dapat menentukan tema slide yang Anda buat background ini dapat berupa gambar dan foto. Anda dapat membuat sebuah foto atau gambar jadi tema atau membuat tema yang berbeda dalam setiap slide.

5. Menu Transition

Fitur yang melengkapi antara lain sebagai berikut.

$\checkmark$ Preview, berfungsi untuk melihat jenis efek transisi yang diterapkan pada slide dan menyesuaikan objek yang disimpan dalam setiap slide.

$\checkmark$ Transition to this slide, merupakan fitur yang berfungsi sebagai salah satu hal utama jika ingin membuat presentasi Anda menarik, karena fitur ini memberi efek transisi pada slide.

$\checkmark$ Timing, fitur ini mengatur lamanya transisi yang diterapkan pada setiap slide, sehingga Anda bisa menyesuaikan timing transisi yang tepat.

6. Menu Animation

$\checkmark$ Preview, fungsinya sama untuk melihat jenis animasi yang akan digunakan dan dipilih sesuai selera.

$\checkmark$ Animation, berfungsi untuk memberikan animasi pada slide yang melibatkan objek pada setiap slide.

$\checkmark$ Advanced animasi, fitur ini pemberi animasi namun animasi yang Anda buat sendiri atau tidak menggunakan animasi bawaan.

$\checkmark$ Timing, berguna untuk mengatur waktu animasi dari pertama muncul hingga animasi selesai. 
7. Slide Show, Reviev daan View

Menu Slide Show berfungsi untuk mengatur slide dalam mode presentasi agar perpindahannya dapat diatur dan segala animasi dan efek transisi bergerak secara otomatis. Menu review digunakan untuk memeriksa kembali ejaan, Istilah dan halhal yang berhubungan dengan fakta yang sudah ada. Menu view berfungsi untuk mengatur mode presentasi. Jika presentasi menggunakan perangkat lain, biasanya diatur menggunakan fitur yang ada di dalam menu view.

\section{RANCANGAN/DESAIN VIDIO PEMBELAJARAN}

\section{Skema Alur Rancangan}

Alat peraga pembelajaran yang kami rancang ini adalah video pembelajaran dengan model lecturing, guru memaparkan materi dengan dilengkapi contoh gambar, animasi dan suara.

\begin{tabular}{|c|c|c|c|}
\hline No & Narasi & Sketsa & Ket \\
\hline 1 & Video kemdikbud & & $\begin{array}{l}\text { Video opening adalah } \\
\text { video kemdikbud }\end{array}$ \\
\hline 2 & $\begin{array}{l}\text { Video intro nama, nama sekolah dan } \\
\text { materi }\end{array}$ & & $\begin{array}{l}\text { Setelah video } \\
\text { opening muncul } \\
\text { video intro nama, } \\
\text { nama sekolah dan } \\
\text { materi }\end{array}$ \\
\hline 3 & $\begin{array}{l}\text { Assalamualaikum warahmatullahi } \\
\text { wabaraqatuh... hallo anak- anak } \\
\text { hebat!!bagaimana kabar kalian hari } \\
\text { ini? Iva alhamdulillah baik-baik saja } \\
\text { yah...semoga kalian selalu sehat dan } \\
\text { tetap semangat belajar... }\end{array}$ & $\square$ & $\begin{array}{l}\text { Logo kemdikbud, logo } \\
\text { rumah belajar, } \\
\text { animasi guru yang } \\
\text { menyapas siswa } \\
\text { dengan salam dan } \\
\text { ada papan nama guru } \\
\text { beserta sekolah }\end{array}$ \\
\hline 4 & $\begin{array}{l}\text { Pada vidio pembelajaran kali ini, kita } \\
\text { akan melanjutkan pelajaran kita } \\
\text { tentang Bentuk Akar, mareti kita hari } \\
\text { ini adalah Operasi bentuk akar yaitu } \\
\text { penjumlahan dan pengurangan bentuk } \\
\text { akar }\end{array}$ & 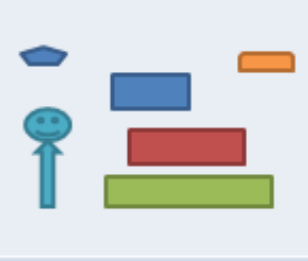 & $\begin{array}{l}\text { Logo kemdikbud, logo } \\
\text { rumah belajar, } \\
\text { animasi guru yang } \\
\text { meginformasikan } \\
\text { materi pelajaran yang } \\
\text { akan di pelajari }\end{array}$ \\
\hline 5 & $\begin{array}{l}\text { Setelah kalian mempelaiari materi } \\
\text { penjumlahan dan pengurangan } \\
\text { bentukakar, kalian diharapkan bisa } \\
\text { melakukan operasi aliabaryang } \\
\text { melibatkan bentuk akar. }\end{array}$ & 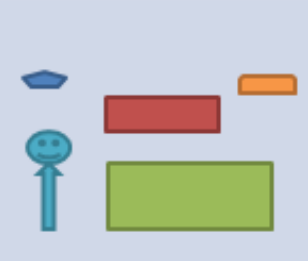 & $\begin{array}{l}\text { Logo kemdikbud, logo } \\
\text { rumah belajar, } \\
\text { animasi guru yang } \\
\text { meginformasikan } \\
\text { tuiuan pembelajaran } \\
\text { yang akan di capai }\end{array}$ \\
\hline
\end{tabular}




\begin{tabular}{|c|c|c|c|}
\hline No & Narasi & Sketsa & Ket \\
\hline 6 & $\begin{array}{l}\text { Sebelum kita mempelajari lebih jauh } \\
\text { tentang penjumlahan dan } \\
\text { pengurangan bentuk akar, terlebih } \\
\text { dahulu kita pelaiari tentang akar } \\
\text { senama dan akar seienis, ini penting } \\
\text { karena nanti akan kita gunakan dalam } \\
\text { perkalian dan pembagian bentuk akar } \\
\text { iuga }\end{array}$ & $\hookleftarrow$ & $\begin{array}{l}\text { Logo kemdikbud, } \\
\text { logo rumah belaiar, } \\
\text { animasi guru yang } \\
\text { meginformasikan } \\
\text { materi awal yang } \\
\text { berkaitan dengan } \\
\text { materi pelaiaran }\end{array}$ \\
\hline 7 & $\begin{array}{l}\text { Yuk kita bahas materi peniumlahan } \\
\text { dan pengurangan bentuk akar... } \\
\text { Peniumlahan dan pengurangan } \\
\text { bentuk akar hanva bisa dilakukan pada } \\
\text { bentuk akar seienis, bentuk umumnva } \\
\text { adalah } \\
p \sqrt{a}+q \sqrt{a}=(p+q) \sqrt{a} \text { dan } p \sqrt{a}- \\
q \sqrt{a}=(p-q) \sqrt{a} \text {, iadi apabila } \\
\text { bentuk akar sudah merupakan akar } \\
\text { seienis kita bisa langsung } \\
\text { meniumlahkan atau mengurangkan } \\
\text { bilangan yang berada di depan akar } \\
\text { tersebut, atau jika bentuk akar tidak } \\
\text { seienis jika maka kita bisa } \\
\text { menyederhanakan dulu meniadi akar } \\
\text { sejenis. untuk lebih ielasnva mari kita }\end{array}$ & $\varpi$ & $\begin{array}{l}\text { Logo kemdikbud, } \\
\text { logo rumah belaiar, } \\
\text { judul materi, } \\
\text { Kotak ringkasan } \\
\text { materi, animasi guru } \\
\text { yang menielaskan } \\
\text { materi pelaiaran }\end{array}$ \\
\hline 8 & $\begin{array}{l}\text { Selesaikan operasi bentuk akar } \\
\text { berikut! }\end{array}$ & 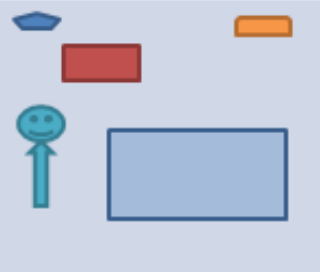 & $\begin{array}{l}\text { Logo kemdikbud, logo } \\
\text { rumah belajar, tulisan } \\
\text { contoh soal, kotak } \\
\text { yang berisi soal-soal, } \\
\text { animasi guru yang } \\
\text { membaca soal - soal }\end{array}$ \\
\hline 9 & $\begin{array}{l}\text { Hal yang perlu diperhatikan dalam } \\
\text { melakukan operasi peniumlahan dan } \\
\text { pengurangan bentuk akar adalah } \\
\text { apakah bentuk akar yang akan } \\
\text { dioperasikan adalah akar yang seienis } \\
\text { atau tidak, nah pada soal ini ternyata } \\
\text { bentuk akarnva tidak sejenis dan } \\
\text { bentuk akar sudah tidak bisa } \\
\text { disederhanakan lagi, iadikita tidak bisa } \\
\text { melakukan operasi peniumlahan pada } \\
\text { model soalseperti ini karena akarnya } \\
\text { tidak seienis }\end{array}$ & $\infty_{\text {tulisan }}$ & $\begin{array}{l}\text { Logo kemdikbud, logo } \\
\text { rumah belaiar, tulisan } \\
\text { soal yang akan } \\
\text { dibahas, anak panah } \\
\text { bertuliskan iawab, } \\
\text { kotak untuk menulis } \\
\text { iawaban soal animasi } \\
\text { guru yang meniawab } \\
\text { contoh soal }\end{array}$ \\
\hline 10 & $\begin{array}{l}\text { Selanjutnya } 12 \sqrt{6}-3 \sqrt{6} \text {, kita } \\
\text { perhatikan di sini ternyata akarnya } \\
\text { merupakan akar sejenis, jadi untuk } \\
\text { melakukan operasi pengurangan kita } \\
\text { bisa langsung mengurangkan bilangan } \\
\text { yang berada di depan akarnya yaitu } \\
(12-3) \sqrt{6}=9 \sqrt{6}\end{array}$ & $\begin{array}{l}\infty \\
\bullet\end{array}$ & $\begin{array}{l}\text { Logo kemdikbud, logo } \\
\text { rumah belajar, kotak } \\
\text { yang berisi contoh } \\
\text { soal dan penjelasan } \\
\text { soal, animasi guru } \\
\text { yang menielaskan } \\
\text { jawaban soal }\end{array}$ \\
\hline
\end{tabular}




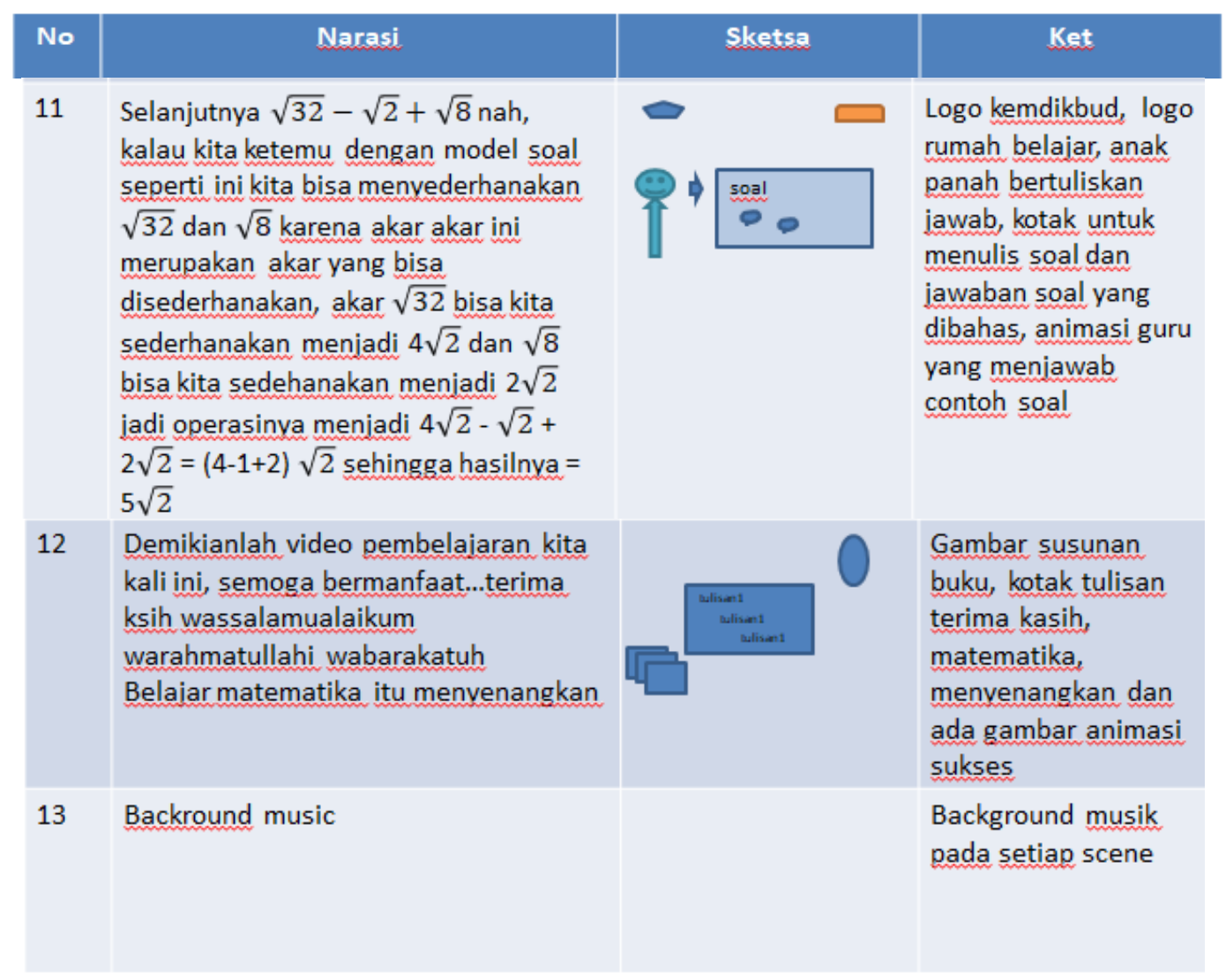

\section{Alat dan Bahan}

Dalam membuat sebuah video pembelajaran yang menarik tentunya membutuhkan peralatan dan software yang menunjang dan mampu membantu membuat video pembelajaran itu sendiri. Adapun alat dan bahan yang dibutuhkan penulis selama membuat aplikasi pembelajaran ini adalah:

1. Alat

\begin{tabular}{|c|c|}
\hline & $\begin{array}{l}\text { untuk editing penulis menggunakan } \\
\text { laptop Lenovo ideapad320 intel core i3 } \\
\text { yang bisa digunakan untuk desain secara } \\
\text { optimal tanpa ada ganguan }\end{array}$ \\
\hline Po. Microsoft PowerPoint 2010 & $\begin{array}{l}\text { Microsoft office } \\
\text { digunakan untuk mendesain slide video } \\
\text { pembelajaran serta aset - aset yang } \\
\text { dibutuhkan untuk membuat video } \\
\text { pembelajaran }\end{array}$ \\
\hline 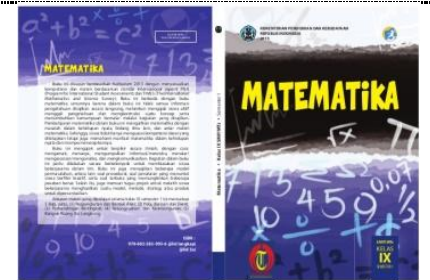 & $\begin{array}{l}\text { buku siswa kurikulum } 2013 \text { digunakan } \\
\text { penulis sebagai pedoman penyusunan } \\
\text { materi yang disajikan dalam video } \\
\text { pembelajaran }\end{array}$ \\
\hline
\end{tabular}

@2021 JPPI (https://bimaberilmu.com/jurnal/index.php/jppi)

Ciptaan disebarluaskan di bawah Lisensi Creative Commons Atribusi 4.0 Internasional

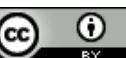




Headphone yang digunakan untuk
merekam audio yang akan dipakai untuk
video pembelajaran, karena headphone
ini mempunyai sound isolation yang baik
atau dengan kata lain headphones ini
kedap suara sehingga tidak ada bocoran
sound yang keluar dari headphones
tersebut.

2. Bahan dan Aset

\begin{tabular}{|l|l|}
\hline Macam - macam gambar \\
background yang digunakan untuk \\
menyajikan materi pembelajaran \\
agar terlihat lebih menarik
\end{tabular}

\section{PROSEDUR PEMBUATAN VIDEO PEMBELAJARAN}

\section{Menentukan Konsep Materi}

Materi di dalam aplikasi pembelajaran ini diambil dari materi pelajaran Buku Siswa dan buku guru Matematika kelas IX kurikulum 2013, Pada materi ini membahas tentang bentuk akar dan sub materi operasi bentuk akar dan lebih spesifiknya materi penjumlahan dan pengurangan bentuk akar, beserta latihan-latihan untuk meningkatkan pemahaman siswa terhadap meteri yang diajarkan.

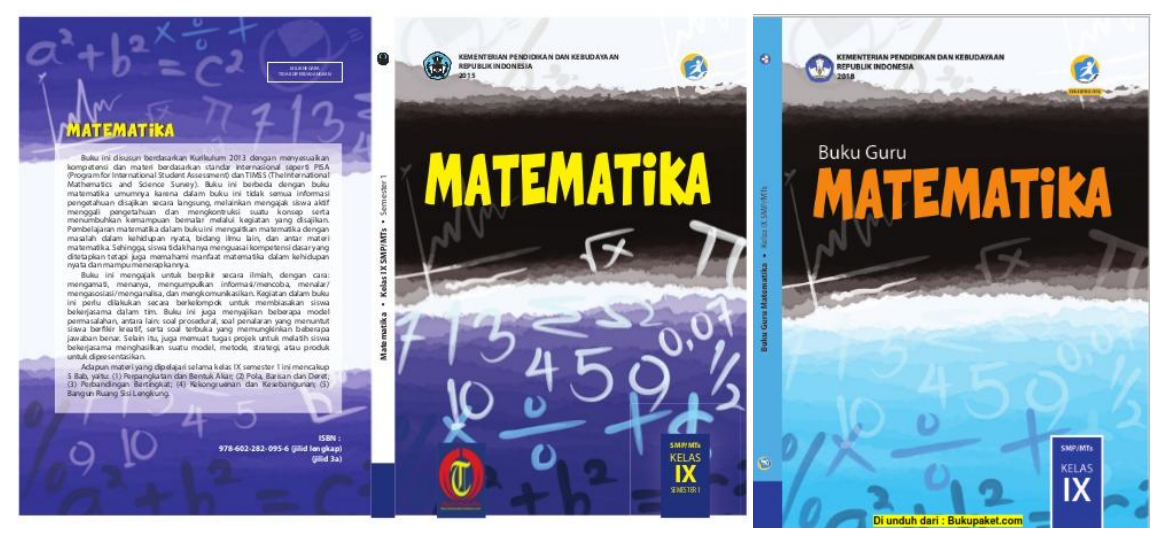



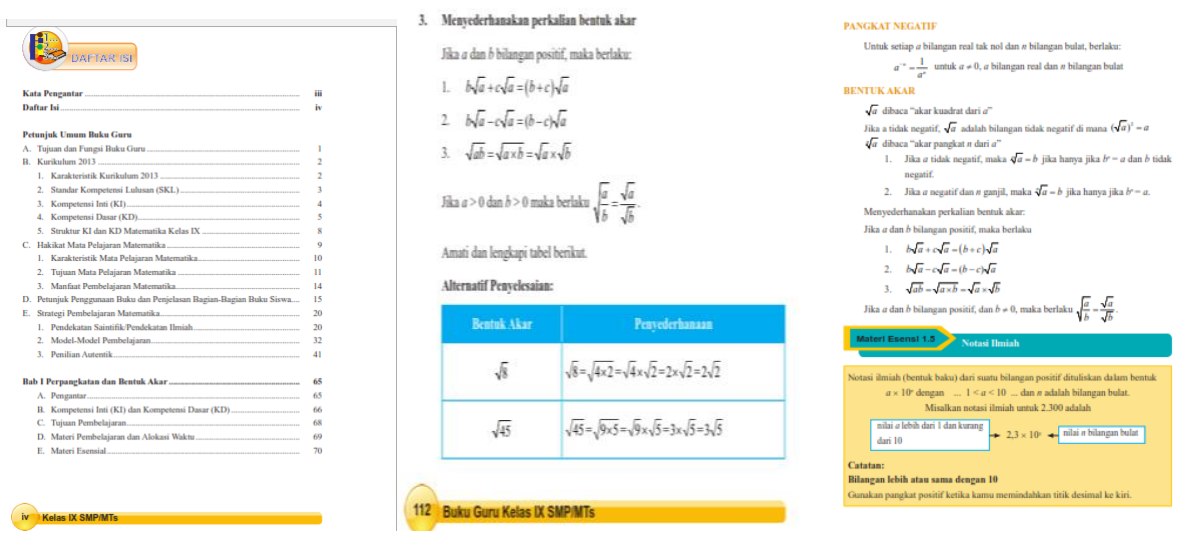

\section{Mendesain Slide Video Pembelajaran}

Slide atau halaman pada video pembelajaran didesain menggunakan Microsoft office powerpoint dengan menampilkan warna- warna yang kontras dan penggunaan font yang terlihat jelas dan tampilan yang menarik.

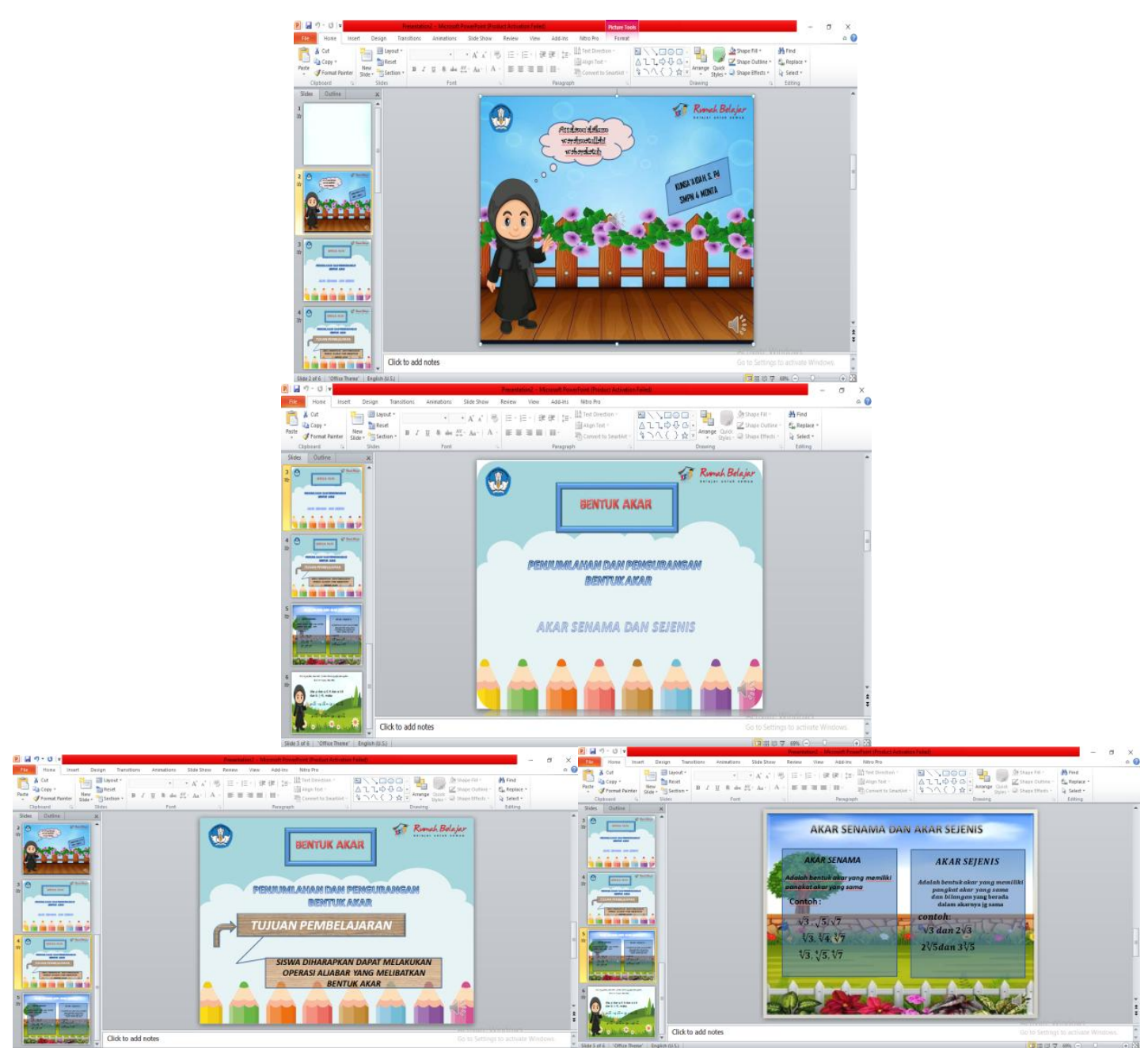

\section{Menambah dan merekam Audio untuk video pembelajaran}

Musik dalam sebuah video mempunyai peranan yang sangat penting sama halnya seperti film yang juga mengakui peran dari soundtrack dan backsound. Video 
atau film tidak akan menarik tanpa melibatkan unsur musik ke dalamnya. Pilihan dan porsi musik yang pas dalam video akan membuat video tampil sempurna.

Menambahkan audio pada video pembelajaran dengan menggunakan aplikasi Microsoft powerpoint dilakukan dengan cara

Pilih menu insert-Audio-from file

* Dalam kotak dialog Sisipkan Audio, pilih file audio yang ingin ditambahkan

\section{Pilih sisipkan}

Jika ingin merekam audio caranya sama seperti menambahkan audio, hanya saja pada menu audio pilih record audio lalu mulai berbicara (Penting: Perangkat Anda harus mengaktifkan mikrofon untuk merekam audio). Untuk meninjau rekaman video, pilih hentikan lalu pilih putar. Pilih Rekam untuk merekam ulang klip Anda, atau pilih OK jika Anda puas. Untuk memindahkan klip, pilih dan seret ikon audio ke tempat yang anda inginkan dalam slide.

\section{Proses Pengambilan Gambar Video menggunakan aplikasi Ms. PowerPoint}

Pada tahap ini mulai dilakukan pengambilan gambar untuk tayangan video. Langkah Pertama, kami menyiapkan alat-alat nya dahulu seperti laptop, headphone, narasi dan slide - slide yang sudah didesain lengkap dengan animasinya menggunakan aplikasi Ms. PowerPoint yang dibutuhkan untuk rekaman videonya. Setelah itu kita buka kembali aplikasi Ms. PowerPoint, dan mencari file yang telah kita desain, langkah selanjutnya adalah membuka file tersebut dan setelah terlihat tampilan Ms. PowerPoint maka yang kita lakukan adalah masuk ke menu Slide show, setelah terbuka tampilan menu slide Show maka kita memilih menu Recording Slide Show selanjutnya ada 2 menu yang harus kita pilih, yaitu start recording from beginning dan start recording from current slide. Jika kita menginginkan untuk merekam semua slide maka kita pilih start recording from beginning, tapi jika kita hanya mengnginkan rekaman hanya untuk slide - slide tertentu maka kita pilih start recording from current slide, dan karena saya akan merekam semua slide maka saya pilih start recording from beginning, selanjutnya muncul kotak dialog sepertii di bawah ini

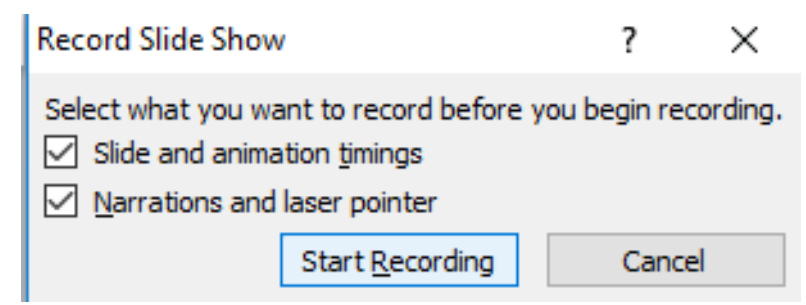

lalu pilih start recording.

Selanjutnya akan muncul slide per slide yang telah kita buat beserta animasinya, sembari slide per slidenya ditayangkan kita pun mulai mengisi audio dengan narasi yang telah sediakan sebelumnya. Pada pembuatan video pembelajaran dengan aplikasi Ms. PowerPoint saya memilih untuk tidak memunculkan wajah, jadi sebagai ganti tampilan wajah kami ganti dengan gambar cartoon yang di animasikan. Setelah sampai pada slide terakhir maka berakhir pula rekaman slide Show dan tampilannya menjadi seperti gambar di bawah ini: 


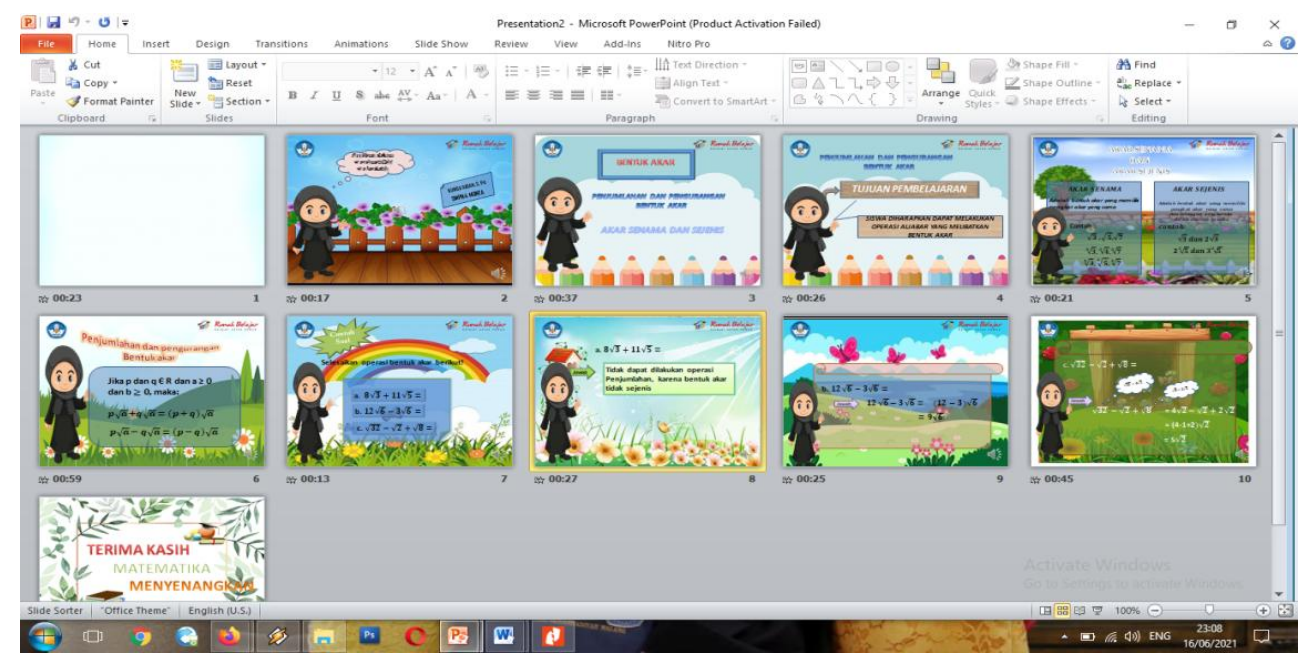

Dengan tampilan terdapat audio dan timing pada setiap slide, dan selanjutnya kita akan ekspor file PowerPoint kita menjadi video. Caranya adalah pilih menu file pada toolbar kemudia pilih save and send seprti pada gambar di bawah ini:

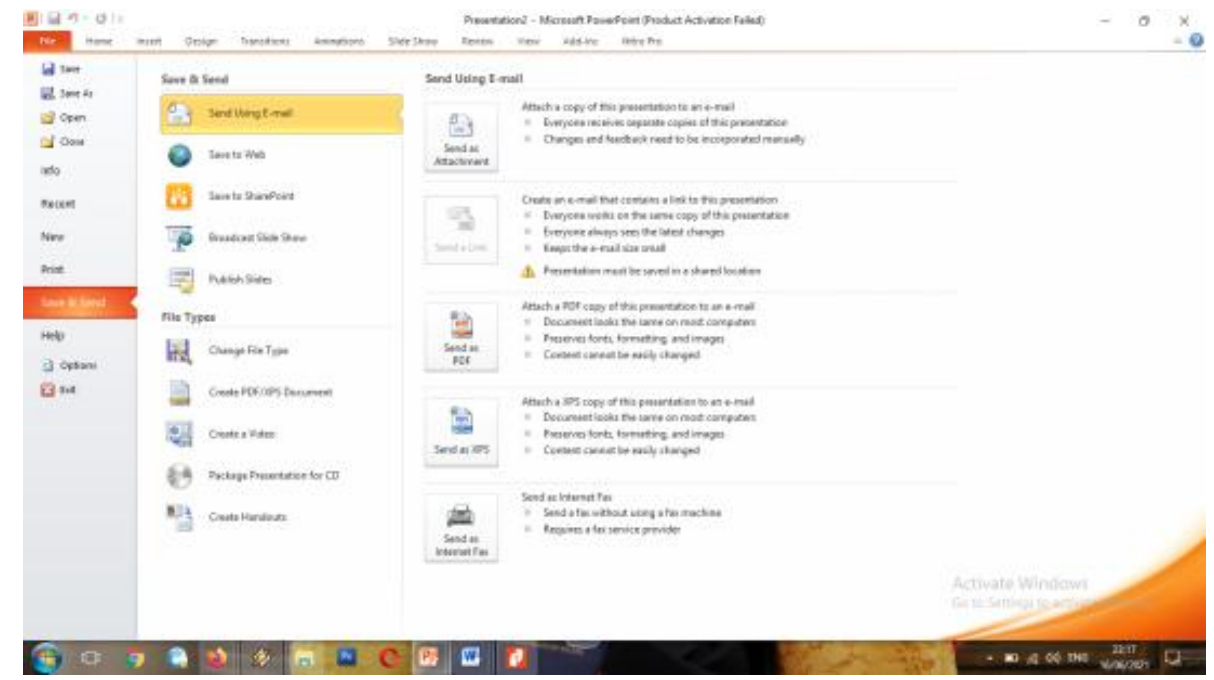

Selanjutnya pilih create a video

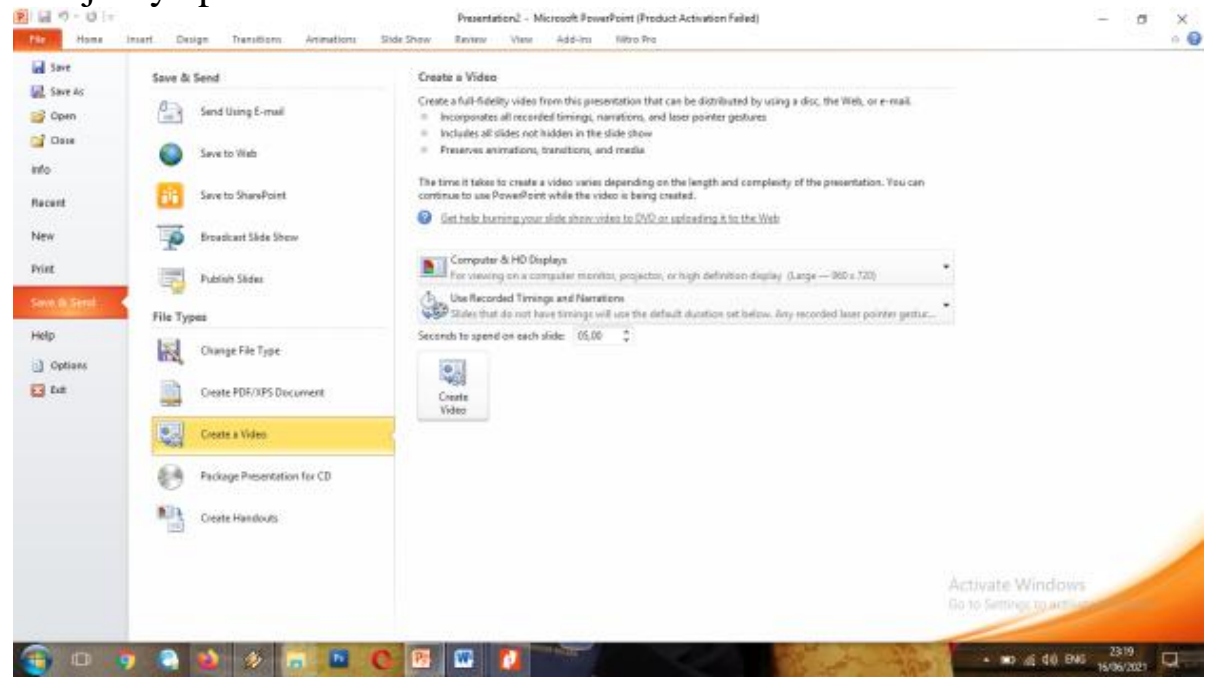

@2021 JPPI (https://bimaberilmu.com/jurnal/index.php/jppi) 
Selanjutnya pilih create video seperti pada gambar di bawah ini:

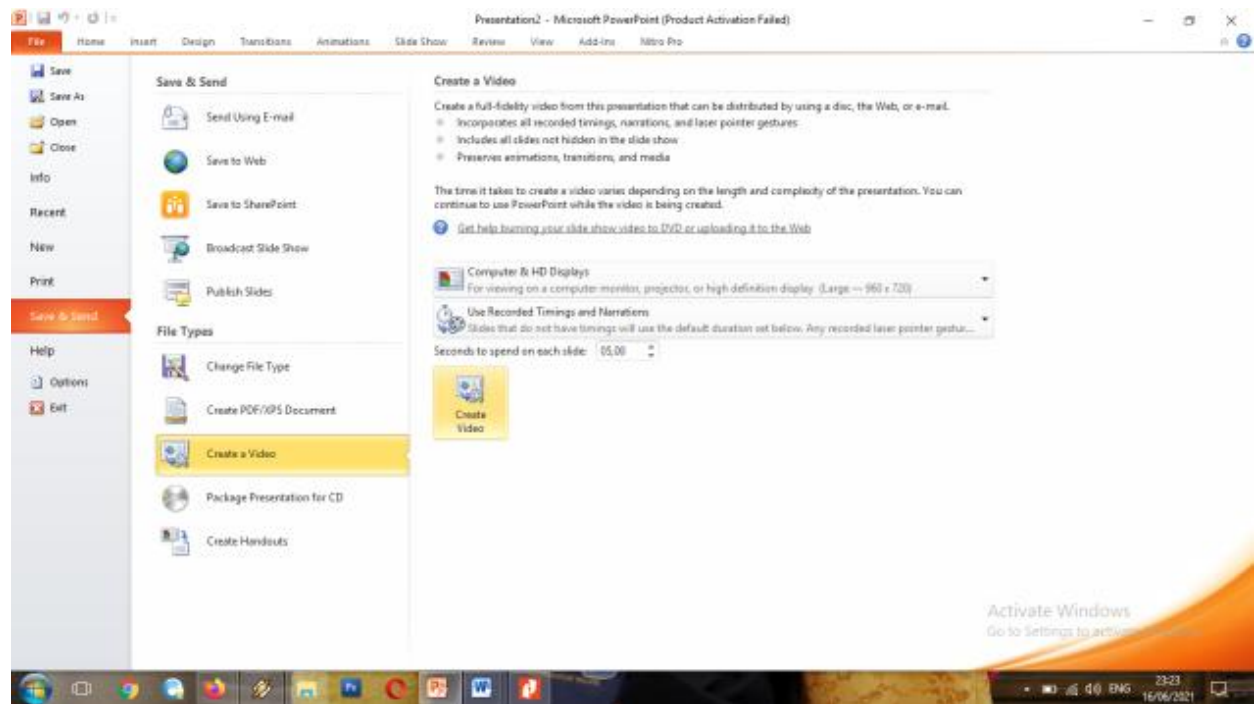

Selanjutnya akan ada tampilan seperti di bawah ini

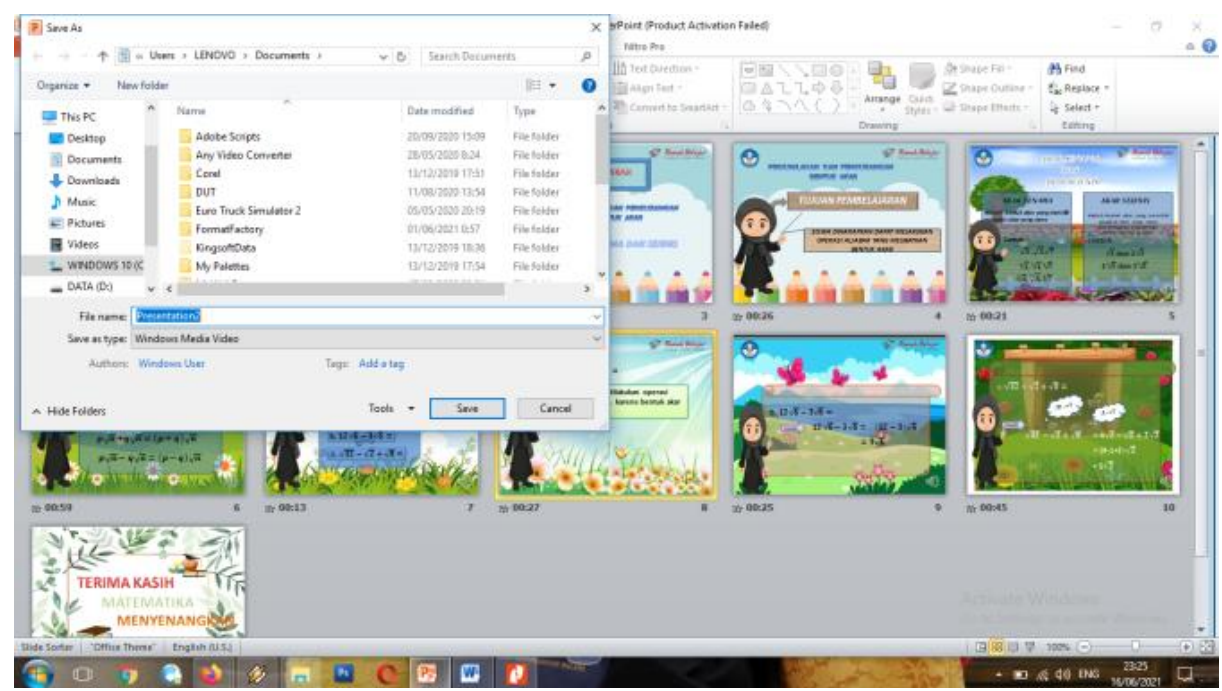

Pada kotak dialog file name kita simpan file kita dengan nama apa saja yang kita inginkan lalu pilih menu save untuk menyimpan video yang sudah kita buat, kita tunggu beberpa saat, setelah tersimpan maka video akan tersimpan di Documen laptop kita. Pilih icon play untuk melihat kembali hasilnya.

\section{KESIMPULAN}

Penerapan media pembelajaran berbasis computer melalui desain video pembelajaran matematika dengan aplikasi microsoft office powerpoint ini memberikan dampak yang baik terhadap siswa SMPN 4 Monta dalam mengikuti dan memahami pembelajaran matematika. Siswa lebih semangat mengikuti pelajaran karena visualisasi vidio yang ditampilkan, kemudian siswa mudah memahami pelajaran matematika karena materi sudah didesain dengan terstruktur. Guru harus mampu melakukan inovasi dalam mengembangkan media pembelajaran, terutama dalam memanfaatkan teknologi komputer. Mengintegrasikan teknologi komputer 
pada mata pelajaran matematika dapat dilakukan pada semua materi, sehingga yang menjadi faktor utama adalah keterampilan guru matematika untuk memanfaatkan teknologi tersebut.

\section{DAFTAR PUSTAKA}

Arief, S. (2009). Media pendidikan, pengertian, pengembangan, dan pemanfaatannya. Jakarta: PT. Rajagrafindo Persada.

Arsyad, A. (1997). Media Pembelajaran. Jakarta: Raja Grafindo Persada.

Bahasa Indonesia (2001). Kamus Besar Bahasa Indonesia : Edisi Ketiga. Jakarta : Balai Pustaka, 2001.

Depdiknas (2003). Undang-Undang Sistem Pendidikan Nasional No. 20 Tahun 2003. Jakarta: Kemdikbud.

Erhans, A. (2011). Microsoft Powerpoint 2010. Jakarta: PT. Ercontara Rajawali.

Hamalik, O.(1986). Metode Belajar dan Kesulitan-kesulitan Belajar. Bandung: Tarsito.

Kemp, J. E., \& Dayton, D. K. (1985). Planning and Producing Instructional Media. Cambridge: Haper \& Row Publishers, New York.

Khotimah, N. K., Ashar, M. U., \& Nurhidayah, N. (2021). Penerapan Metode Diskusi Berbasis E-Learning dengan Penggunaan Aplikasi Edmodo, Zoom Cloud Meeting dan Quizizz untuk Meningkatkan Hasil Belajar Mahasiswa Materi Sistem Pencernaan pada Program Studi Keperawatan UIN Alauddin Makassar. Jurnal Pendidikan dan Pembelajaran Indonesia (JPPI), 1(1), 61-71.

Miarso, Y. (1984). Definisi Teknologi Pembelajaran: Satuan Tugas dan Terminologi. Jakarta: Rajawali Press.

Syarifuddin, S., Basri, H., Ilham, M., \& Fauziah, A. F. (2021). Efektifitas Pembelajaran Daring Mahasiswa Pendidikan Matematika ditengah Pandemi Covid-19. JagoMIPA: Jurnal Pendidikan Matematika dan IPA, 1(1), 1-8. 